$\xi=-1$

\title{
Pomegranate Juice Induced Cell Cycle Arrest and Apoptosis via Mitochondrial Pathway in Human Lung Adenocarcinoma A549 Cells
}

\author{
Radiah Abdul Ghani ${ }^{1 *}$, Nik Nurasyikin Nik Abdul Malek ${ }^{1}$, Norzamzila Abdullah ${ }^{2}$ \\ ${ }^{l}$ Department of Biomedical Science, Kulliyyah of Allied Health Sciences, International Islamic University Malaysia \\ ${ }^{2}$ Department of Basic Medical Science, Kulliyyah of Medicine, International Islamic University Malaysia \\ *Corresponding author E-mail: radiah@iium.edu.my
}

\begin{abstract}
Lung cancer is the most common type of cancer which the mortality rate increases year by year. Therapeutic drugs could not control the progression of cancer and it contributes to the side effects in normal cells. Thus, an alternative strategy using natural product becomes a focus today. Punica granatum, known as pomegranate has demonstrated the anti-proliferative effect in A549 cells. To further confirm its efficacy, this study aimed to investigate the type of cell death and its pathway in A549 cells. Propium Iodide staining was applied to determine the cell cycle profile changes induced by this juice. The determination of type of cell death was done using Annexin-V staining and later will be analysed using flowcytometer. The pathway to apoptosis was investigated by determining the caspase- 3, 8 and 9 activities. The findings were supported by mitochondrial membrane permeability assay and cytochrome c release detection which were later analysed using flowcytometer. This study revealed that pomegranate juice induced cell cycle arrest at G0/G1 phase and apoptosis through intrinsic pathway following $24 \mathrm{~h}$ treatment. Pomegranate juice caused loss of mitochondrial membrane permeability after $48 \mathrm{~h}$ [p<0.05] exposure and a release of cytochrome $\mathrm{c}$ in cytosol after $24 \mathrm{~h}$ [p<0.05] and $48 \mathrm{~h}$ [p<0.01] exposure in treated A549 cells. In caspases analysis, it was showed that there was activation of caspase- 3 following $72 \mathrm{~h}$ [p $<0.01]$ treatment and caspase- 9 after 48 [p<0.01] and $72 \mathrm{~h}[\mathrm{p}<0.05]$ exposure in treated A549 cells. It can be concluded that pomegranate juice able to cause A549 cell growth inhibition by inducing cell cycle arrest and apoptosis through mitochondrial pathway.
\end{abstract}

Keywords: apoptosis; caspases ; mitochondria permeability ; lung cancer; pomegranate juice

\section{Introduction}

Cancer has become a major public issue that leads to increased mortality rate worldwide. Lung cancer was known to be the most common form of cancers related death (1). There are several existing conventional therapies including chemotherapy, radiotherapy and surgical approaches which are aimed to treat cancer. However, the survival rate for cancer is still not showing a good improvement since last decades especially lung cancer which is $5 \%$ in the world (2). Due to high cancer prevalence and poor survival rate, other alternatives to reduce the risk of getting cancer as well as to prevent the recurrence of cancer must be investigated. It is about $40 \%$ of cancer cases could be prevented because most of the cancer cases are related to major lifestyle. Due to this, cancer treatment and prevention using natural product has gained attention and developed as a major field of scientific investigation. Cancer prevention is an option in reducing the risk of getting cancer as well as preventing cancer recurrence by using either synthetic or natural compounds that may prevent the development of invasive cancer (3).Thus, as it can prevent the growth of cancer cells, cancer prevention could be a possible alternative to chemotherapy (4).

Natural compounds in fruits and vegetables have a potential to be cancer preventive agents as diets high in fruits and vegetables (>400 g/d) may prevent at least $20 \%$ of all cancers (3). Punica granatum or pomegranate which is categorized under prophetic foods and medicine had been known to contribute in cancer prevention. It was known as a "healing food" because of the phytonutrients derived from it offer the best protection against various diseases (5). Pomegranate also possesses beneficial properties including antitumor, anti-inflammatory, antioxidant and antidiabetic properties. The pomegranate fruits are widely consumed fresh and recently in beverage form as juice. The use of juice, peel and oil of pomegranate has been shown to possess anticancer activity (6).

According to Saunders \& Wallace (4), the natural cancer preventive agents are found as a complex mixture, not in isolation. Therefore, the action of the agents is likely to be the result of different bioactive compounds which affect multiple pathways to produce a cumulative effect. With regard pomegranate juice, we recently showed that pomegranate juice possesses remarkable antiproliferative effect in A549 cells at 2\% (v/v) concentration (5). In this study, the effect of pomegranate juice in A549 cells thus seemed promising due to its capability to suppress A549 cell growth which has been measured using Trypan blue exclusion assay and MTT assay. This is in line with previous studies which has proven that pomegranate is able to possesses inhibitory effects on other cancer cells such as breast cancer cells, MCF-7 (7),colon (8) and pancreatic cancer (9).

To further confirm its efficacy, it is highly crucial to determine the type of cell death induced in cancer cells. This is reflecting the ultimate goal of cancer treatment or prevention which is to pro- 
mote the death of cancer cells without causing damage to normal cells (10). In cancer treatment, using anticancer agents that induce apoptosis are highly recommended due its possibility to less harmful to healthy cells. Besides, cell cycle arrest also becomes the target in cancer treatment. Generally, cancer occurs as a result of dysregulation of cell cycle which serves to protect from DNA damage. Whenever DNA damage occurs, cell cycle arrest provides tumor cells to undergo repairs mechanism. However, failure to repair the DNA damage will cause activation of apoptotic cascade which leads to cell death. Therefore, this study aimed to investigate the effect of pomegranate on cell cycle distribution as well as cell death mechanism in human lung adenocarcinoma cells, A549.

\section{Literature Review}

\subsection{Punica Granatum (Pomegranate)}

Phytochemicals had been known to play an important role in inhibiting cancer development by targeting one or more signaling intermediates leading to induction of apoptosis (11). One of the natural products that contribute to cancer prevention is Punica granatum L. or pomegranate. The pomegranate fruit has been used for centuries in ancient cultures for its medicinal purposes. Pomegranate had been chosen in this study because of its medicinal properties including anti-tumor property. It is believed that phyto-nutrients derived from pomegranate offer the best protection against many diseases where it has been regarded as a "healing food" with numerous beneficial effects in several diseases including antitumor, anti-inflammatory, antioxidant and antidiabetic properties (6).

Pomegranate belongs to the family Punicaceae. It is categorized under medicinal fruits recommended by Prophet Muhammad (pbuh). According to Al-Qur'an, pomegranate grows in the gardens of paradise and it is mentioned three times in the Al-Qur'an as an example of God's good creation. It is widely cultivated throughout Iran, India, Mediterranean countries, the drier parts of Southeast Asia, Malaysia, the East Indies, and tropical Africa and to some extent, in the United States, China, Japan and Russia (12). The use of juice, peel and oil of pomegranate has also been shown to possess anticancer activities, including interference with tumor cell proliferation, cell cycle, invasion and angiogenesis (13). Previous study discovered that pomegranate fruit extract (PFE) possesses remarkable antitumor-promoting effects on mouse skin and anti-proliferative and pro-apoptotic effects in prostate cancer (14). Recently, they reported that PFE inhibits pro-survival signaling pathways in human lung carcinoma A549 cells and inhibit tumor growth in athymic nude mice. Treatment of $50-150 \mu \mathrm{g} / \mathrm{ml}$ of PFE for 72 hours on A549 cells caused a significant decrease in cells viability and dose-dependent arrest of cells in G0/G1 phase of the cell cycle (6).

\subsection{Cell Cycle Distribution}

The cell cycle is known as a recurring process which important for cell replication and division. Cell cycle comprises of four phases which are G1, the first gap or growth phase, S, the DNA synthetic phase, G2, the second gap or growth phase, and M, the mitotic phase. In G1 phase, the cell will grow larger and prepare for DNA replication during $\mathrm{S}$ phase. When the cell reached an appropriate size, cells will exit G1 phase and enter the next phase which is $S$ phase. This phase is crucial for cells as DNA replication as well as proteins and enzymes synthesis occurs. Once the DNA replication is completed, cells will then enter the next phase which is G2 phase. During this phase, cells will grow more and prepare for mitosis. In mitosis, cell division occurs where the cells divide the DNA and cytoplasm to form two new cells. In cell cycle, there are two checkpoints which control the cell cycle from any damage. The first checkpoint is known as G1 checkpoint. It is responsible to sense any DNA damage before cells enters the $\mathrm{S}$ phase. If there is any aberrant of DNA, the action of cyclin dependent kinase (cdk2) will be inhibited which stops the progression of the cell cycle until the damage can be repaired. The second checkpoint is known as G2 checkpoint. Similar to G1 checkpoint, it is also function to sense any DNA damage but G2 checkpoint will check for any DNA damage before cells enter the $M$ phase. If there is any aberrant of DNA, the action of cyclin dependent kinase [cdk1] will be inhibited which prevent the mitosis from occurring. These checkpoints are important to ensure the progression of cell cycle occur without any interruption.

\subsection{Cell Death Pathways}

There are two types of programmed cell death which decide the fate of cells of malignant neoplasms which are apoptosis and necrosis. They are distinguished by their morphological differences. Apoptosis, an active, gene-regulated form of cell death, is the major type of cell death which is characterized by specific morphological and biochemical changes of dying cells. The morphological changes include cell shrinkage, nuclear condensation and fragmentation,membrane blebbing and loss of adhesion to neighbours or to extracellular matrix while biochemical changes include chromosomal DNA cleavage into inter nucleosomal fragments (15). On the other hand, necrosis is considered as accidental cell death, a random, uncontrolled process which caused profound effects on malignant cells. According to Ouyang et al (11), necrosis usually involves cell swelling, organelle dysfunction and cell lysis. Necrosis also disrupts the integrity of the cells membrane which caused the release of intracellular materials, leading to inflammatory response by immune cells.

Apoptosis, a preferential way of elimination of damaged cells is regulated and controlled by a group of endoproteases known as caspases. Caspases play an important role in maintaining homeostasis through regulating cell death and inflammation. Caspases have been broadly categorized by their known functions in apoptosis [caspase- $3,-6,-7,-8$ and -9 in mammals] and in inflammation [caspase-1, - $4,-5$ and -12 in humans] (15). Initially, caspases are produced as inactive monomeric procaspases which require dimerization and cleavage for activation. There are two types of caspases which are initiator [caspases-8 and -9] and executioner caspases [caspases-3, -6 and -7]. In apoptosis, executioner caspases are activated by initiator caspases. Various apoptotic pathways exist and most apoptotic programs fall into either extrinsic (death receptor mediated) or intrinsic (mitochondrial mediated) pathway. The extrinsic apoptotic pathway is activated at the cell surface.The binding of pro-apoptotic ligands to the respective plasma membrane-localized receptors causes the monomeric procaspase- 8 to be recruited to the death-inducing signaling complex [DISC] (15) which then results in dimerization and activation. McIlwain and colleagues reviewed that there are two outcomes resulted from the death receptor mediated activation of caspase- 8 which are actually depends on the cell types. In type I cells, apoptosis is initiated directly by cleaving and activating the executioner caspases [caspase-3) whereas in type II cells, caspase- 8 must first activate the intrinsic apoptotic pathway in order to induce cell death.

\section{Methodology}

\subsection{Preparation of Pomegranate Juice}

A concentrated pomegranate juice which manufactured by Gulsan Gida Co. was used in this study. It is $100 \%$ natural juice and contains no added sugar or sweeteners. The sample had been sent for sample analysis in order to identify the content of pomegranate juice and it is found that the preservative is below detection limit [ULUKM/1285/16]. For experiment, the sample was diluted to the concentration required by diluting the pure $100 \%$ pomegranate 
juice as the stock solution to working concentration. The working sample was prepared freshly in all experiments. The pomegranate juice was stored and kept refrigerated at $4{ }^{\circ} \mathrm{C}$.

\subsection{Cell Culture Maintenance}

The A549 cells, a human lung adenocarcinoma cell line, were grown in Dulbecco's Modified Eagle Medium [DMEM] with high glucose and L-glutamine supplemented with $10 \%$ [v/v] fetal bovine serum [FBS] and $1 \%$ [v/v] Penicillin-Streptomycin. The cells were grown at $37{ }^{\circ} \mathrm{C}$ in a $\mathrm{CO}_{2}$ incubator until the cells reached 70 $-80 \%$ cellular confluence. The cells were seeded in $5 \mathrm{~cm}^{2}$ diameter cell culture plates at $1.0 \times 10^{4}$ and grown for $48 \mathrm{~h}$ prior treatment.

\subsection{Analysis of Cell Cycle Profile}

A549 cells treated with pomegranate juice $[2 \%(\mathrm{v} / \mathrm{v})]$ at several time exposures [0-72 h] were harvested and collected into $15 \mathrm{~mL}$ falcon tubes. The cells were washed with ice-cold PBS and resuspended in $300 \mu \mathrm{L}$ of PBS. The cells were fixed and permeabilized with $700 \mu \mathrm{L}$ of $70 \%$ cold ethanol at $-20{ }^{\circ} \mathrm{C}$ overnight. On the next day, cells were washed and followed by centrifugation at $850 \mathrm{~g}$. The supernatant was discarded and the cell pellet was resuspended with $250 \mu \mathrm{L}$ of PBS. Then, the cells were treated with $5 \mu \mathrm{L}$ of $10 \mathrm{mg} / \mathrm{mL}$ ribonuclease A [RNase A] at $37{ }^{\circ} \mathrm{C}$ for 1 hour and followed by the staining with $10 \mu \mathrm{L}$ of $1 \mathrm{mg} / \mathrm{mL}$ propidium iodide [PI] at $4{ }^{\circ} \mathrm{C}$ in the dark for 30 minutes. After staining, the cell cycle distribution was analyzed by using flow cytometer.

\subsection{Quantification of Apoptosis by Annexin V Labelling}

A549 cells treated with pomegranate juice $[2 \%(\mathrm{v} / \mathrm{v})]$ at several time exposures [0-72 h] were harvested and collected into $15 \mathrm{~mL}$ falcon tubes. The cells were re-suspended in complete growth medium to approximately $2.0 \times 10^{5}$ to $1.0 \times 10^{6}$ cells $/ \mathrm{mL}$ followed by the addition of Guava Nexin reagent for the detection of apoptosis following the manufacturer's [Guava Nexin] protocols. The samples were immediately analyzed using flow cytometer.

\subsection{Caspase-3, -8 and -9 Analyses}

A549 cells treated with pomegranate juice $[2 \%(\mathrm{v} / \mathrm{v})]$ at severa time exposures [0-72 h] were harvested and collected into $15 \mathrm{~mL}$ falcon tubes. The cells were re-suspended in complete growth medium followed by the addition of caspase reagents following the manufacturer's [Guava ${ }^{\circledR}$ Caspase-3/7 FAM, Guava ${ }^{\circledR}$ Caspase8 FAM \& Abcam Caspase-9 FITC] protocols. The samples were kept on ice and immediately analyzed using flow cytometer.

\subsection{Mitochondrial Membrane Potential (MMP)}

A549 cells treated with pomegranate juice $[2 \%(\mathrm{v} / \mathrm{v})]$ at several time exposures [0-72 h] were harvested and collected into $15 \mathrm{~mL}$ falcon tubes. The cells were re-suspended in warm medium, PBS to approximately $1.0 \times 10^{6}$ cells $/ \mathrm{mL}$ followed by the addition of JC1 dye following the manufacturer's [MitoProbe ${ }^{\mathrm{TM}} \mathrm{JC}-1$ assay kit for flow cytometer] instructions. A mitochondrial membrane potential disrupter, CCCP was used for the positive control. The samples were kept on ice and immediately analyzed using flow cytometer.

\subsection{Cytochrome C Release}

Briefly, A549 cells were seeded on 6 well plates and were allowed to grow for 48 hours. After 48 hours, the cells were treated with $2 \%$ pomegranate juice or left untreated and incubated for various exposure times between 0 - 72 hours. At the end of the exposure period, the cells were harvested and were spun down at $300 \mathrm{~g}$ for 5 to 7 minutes. Then, the supernatant was discarded and $200 \mu \mathrm{L}$ of 1X PBS was added to each tubes. After that, the supernatant was aspirated off and $100 \mu \mathrm{L}$ of permeabilization buffer working solution was added to each tube and incubated on ice for 10 minutes followed by $100 \mu \mathrm{L}$ of fixation buffer working solution which incubated at room temperature for 20 minutes. Following incubation, the samples were spun down at $300 \mathrm{~g}$ for 5 to 7 minutes. About $150 \mu \mathrm{L}$ of $1 \mathrm{X}$ blocking buffer was added to each sample and were mixed thoroughly and incubated at room temperature for 30 minutes. Following incubation, $10 \mu \mathrm{L}$ of either the Anti-IgG1FITC Isotype Control or Anti-Cytochrome c-FITC Antibody was added to each sample and $100 \mu \mathrm{L}$ of $1 \mathrm{X}$ blocking buffer was added before the samples were spun down at $300 \mathrm{~g}$ for 5 to 7 minutes. The supernatant was aspirated off and $200 \mu \mathrm{L}$ of $1 \mathrm{X}$ blocking buffer was added to each sample before being analyzed using flow cytometer.

\subsection{Statistical Analyses}

All statistical analysis was carried out with Prism [Graph Pad, San Diego]. Results were expressed as means [S.E.M] of the number of experiments. Two-way ANOVA with Bonferroni post-test was used to analyze between untreated and treated groups with different time exposures. P values $<0.05$ were considered significant.

\section{Results and Findings}

\subsection{Pomegrenate Induce Cell Cycle Arrest}

To validate the pomegranate as a good anticancer agent, its ability to arrest the cell cycle and induce apoptosis were aimed to be assessed. Most of the anticancer drugs have been found to induce cell cycle arrest and it is also becomes a target in cancer prevention. For instance, etoposide halted the G2/M checkpoint in human cervical cancer cells, HeLa (16). Previous studies also reported that natural dietary cancer preventive compounds including ()-epigallocatechin gallate [EGCG] in green tea, resveratrol in grapes, curcumin in turmeric, lycopene in tomatoes, and quercetin in cranberry induced cell cycle arrest in several cell lines (4). According to this study, with regard to cell cycle distribution analysis, $2 \%[\mathrm{v} / \mathrm{v}]$ pomegranate juice caused an accumulation of cells at G0/G1 phase in treated A549 cells after 24 hours [p<0.001] and 72 hours $[p<0.05]$ exposure [Figure 1]. Thus, pomegranate juice caused cell cycle arrest at G0/G1 phase. This is different from a previous study done in colon cancer and breast cancer cells where pomegranate juice arrested cell cycle and G2/M and G1, respectively (14). The difference might cause by different types of cancer cell and the concentration of the pomegranate juice used. In study done by Khan et al, $25 \%$ [v/v] of juice extract was dosed against colon cancer cells compared to $10 \%[\mathrm{v} / \mathrm{v}]$ used in this A549 cells.

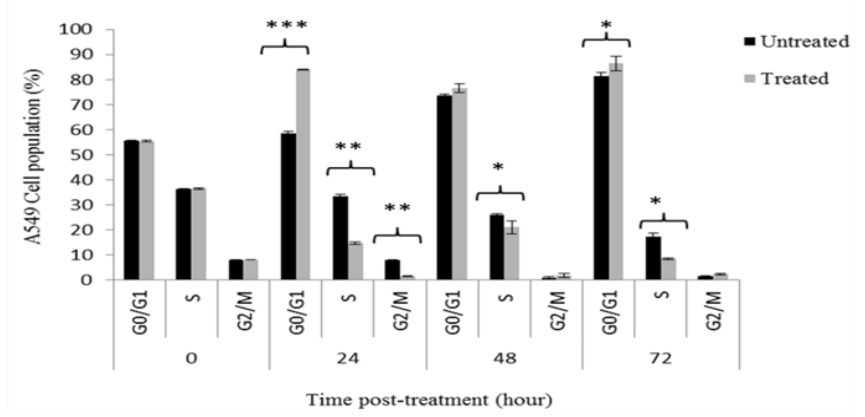

Fig 1: Effect of 2\% pomegranate on A549 cell cycle profile. The cell cycle profile changes in A549 cells were determined using propidium iodide staning. The results were expressed as mean \pm S.E.M $(n=3)$. Statistical analysis was done using two-way ANOVA with Bonferroni post-test (* where $\mathrm{p}<0.05$, ** $\mathrm{p}<0.01$ and $* * * \mathrm{p}<0.001$ when compared between untreated and treated samples of each cell cycle phase). 


\subsection{Pomegranate Induces Apoptosis in A549 Cells}

There are several types of cell death including apoptosis and necrosis. To discriminate between apoptosis and necrosis, Annexin$\mathrm{V}$ staining was used. Following 24 hours of treatment, Annexin-V staining was detected [Table 1], indicating that these cells were undergoing apoptosis. The time-course Annexin V-PE assay between $0-72$ hours exposures discovered that pomegranate juice induced apoptosis with the presence of apoptotic cells following 24 hours treatment of pomegranate juice. The apoptosis of A549 cells induced by pomegranate juice is important because it is a physiological process that is crucial mechanism of cells homeostasis and is considered as the preferred way to eliminate unwanted cells (14). The finding was supported with the previous study which showed increasing concentrations of pomegranate fruit peel extract (PPE) significantly increased the apoptotic cell number after 48 and 72 hours exposures in MCF-7 cells (17).

Table 1: Detection of apoptosis in A549 cells using Annexin-V staining

\begin{tabular}{|c|c|c|c|c|}
\hline $\begin{array}{l}\text { Time } \\
\text { (hour)/ } \\
\text { Percentage } \\
\text { of cells in } \\
\text { each quad- } \\
\text { rant }(\%)\end{array}$ & $\begin{array}{l}\text { Q1 - Viable } \\
\text { cells }(\%)\end{array}$ & $\begin{array}{l}\text { Q2 - Early } \\
\text { Apoptotic } \\
\text { cells }(\%)\end{array}$ & $\begin{array}{l}\text { Q3 - Late } \\
\text { Apoptotic } \\
\text { or ne- } \\
\text { crotic } \\
\text { cells }(\%)\end{array}$ & $\begin{array}{l}\text { Q4 - Dead } \\
\text { cells }(\%)\end{array}$ \\
\hline $\begin{array}{c}\mathbf{0} \\
\text { Untreated } \\
\text { Treated } \\
\end{array}$ & $\begin{array}{l}98.8(0.15) \\
98.9(0.12) \\
\end{array}$ & $\begin{array}{l}0.5(0.00) \\
0.4(0.06)\end{array}$ & $\begin{array}{l}0.3(0.09) \\
0.4(0.00)\end{array}$ & $\begin{array}{l}0.4(0.06) \\
0.4(0.07)\end{array}$ \\
\hline $\begin{array}{c}\mathbf{2 4} \\
\text { Untreated } \\
\text { Treated } \\
\end{array}$ & $\begin{array}{l}98.7(0.20) \\
95.0(0.35)^{*}\end{array}$ & $\begin{array}{l}0.4(0.00) \\
3.8(0.55)^{* * *}\end{array}$ & $\begin{array}{l}0.2(0.06) \\
1.1(0.13)\end{array}$ & $\begin{array}{l}0.7(0.26) \\
0.1(0.07)\end{array}$ \\
\hline $\begin{array}{c}\mathbf{4 8} \\
\text { Untreated } \\
\text { Treated } \\
\end{array}$ & $\begin{array}{l}98.4(0.03) \\
93.3(0.67)^{* * *}\end{array}$ & $\begin{array}{l}0.7(0.06) \\
4.0(0.07)^{* * *}\end{array}$ & $\begin{array}{l}0.5(0.06) \\
2.0(0.35)^{*}\end{array}$ & $\begin{array}{l}0.4(0.15) \\
0.8(0.30)\end{array}$ \\
\hline $\begin{array}{c}2 \\
\text { Untreated } \\
\text { Treated } \\
\end{array}$ & $\begin{array}{l}97.0(0.45) \\
88.3(1.86)^{* * * *}\end{array}$ & $\begin{array}{l}1.5(0.34) \\
9.0(0.79)^{* * *}\end{array}$ & $\begin{array}{l}0.9(0.24) \\
1.9(0.71)\end{array}$ & $\begin{array}{l}0.7(0.19) \\
0.8(0.38)\end{array}$ \\
\hline
\end{tabular}

A549 cells were seeded at $1 \times 10^{4}$ cells $/ \mathrm{ml}$ in $5 \mathrm{~cm}^{2}$ culture dishes for $48 \mathrm{~h}$. After this time, the cells were treated with $2 \%$ pomegranate juice or left untreated for $0,24,48$ and $72 \mathrm{~h}$. After each time of exposure, plates were harvested and cells were stained with Annexin V-PE and analyzed by flow cytometry. Four quadrants (Q) represent viable cells (Q1), early apoptosis (Q2), late apoptosis (Q3) and dead cells (Q4). Data is the mean \pm S.E.M $(\mathrm{n}=3)$. Results were analyzed statistically using two-way ANOVA with Bonferroni's post-test $(*$ where $\mathrm{p}<0.05$ and $* * *$ where $\mathrm{p}<0.001)$ compared to untreated control on each $\mathrm{Q}$.

\subsection{Pomegranate Causes Cell Death through Intrinsic Apoptotic Pathway in A549 Cells}

In most cell lines, apoptosis occurs either via death receptor pathway [extrinsic pathway] or via mitochondrial pathway [intrinsic pathway]. In this study, the possible mechanisms involved in the apoptotic pathway were determined by investigating the effect of pomegranate juice on the caspase activation and mitochondrial membrane permeability. The result of the study showed that caspase-3 was activated [Figure 2], suggesting pomegranate juice induced apoptosis through caspase-dependent pathway. The results also showed that caspase-9 was activated which indicates pomegranate juice induced apoptosis through mitochondrial pathway. No activation of caspase- 8 was observed in the study.

\subsection{Pomegranate Disrupt the Mitochondrial Membrane Potential (MMP) in A549 Cells}

In relation to section 4.3 , this finding is supported by the mitochondrial membrane permeability [MMP] loss in the cells treated with pomegranate juice. A membrane-permeable cationic fluorochrome, JC-1, was used to evaluate the mitochondrial membrane permeability in A549 cells. JC-1 aggregates dissipate into monomers when the mitochondrial membrane permeability collapses and this change will result a shift in fluorescence detected using flow cytometer. Loss of mitochondrial membrane potential is one of the early events in apoptosis through mitochondrial pathway. In order to investigate the role of mitochondria in pomegranate induced apoptosis, the ability of pomegranate juice to induce alterations in mitochondrial potential was determined.

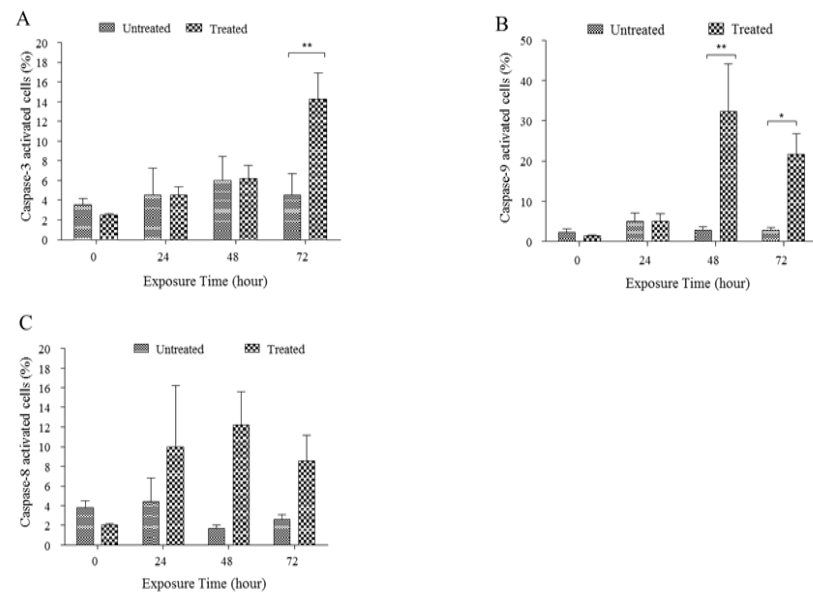

Fig 2: Induction of caspase-mediated apoptosis by pomegranate in A549 cells. Flow cytometry analysis of (A) caspase-3, (B) caspase-9 and (C) caspase- 8 activation in A549 cells treated with $2 \%(\mathrm{v} / \mathrm{v})$ pomegranate juice for $0-72 \mathrm{~h}$. Data represent the mean \pm S.E.M. of at least 3 independent experiments. Two-way ANOVA test was performed to determine the significance $(* \mathrm{p}<0.05, * * \mathrm{p}<0.01$ and $* * * \mathrm{p}<0.001)$.

The result showed that pomegranate juice caused the loss of mitochondrial membrane potential [Figure 3] which could be linked with the induction of apoptosis in A549 cells. Previous studies also showed pomegranate juice triggered apoptosis with significant increases in loss of MMP in several cell lines such as U266 multiple myeloma cells (18), human colon cancer cells (6) and prostate cancer cell (19).

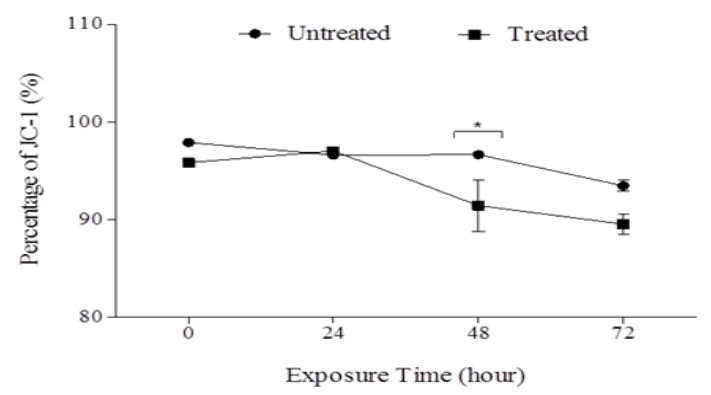

Fig 3: Pomegranate causes loss of mitochondrial membrane potential. Mitochondrial membrane potential (MMP) was assessed using flow cytometer using JC- 1 dye staining. Data represent the mean \pm S.E.M. of at least 3 independent experiments. Two-way ANOVA test was performed to determine the significance $(* \mathrm{p}<0.05, * * \mathrm{p}<0.01$ and $* * * \mathrm{p}<0.001)$.

\subsection{Detection of Cytochrome C}

Mitochondria play a crucial role in the generation of energy for the cell and the events associated with apoptosis. Loss of mitochondrial membrane permeability causes the release of soluble intermembrane proteins such as cytochrome c. The release of cytochrome $\mathrm{c}$ from mitochondria to cytosol is an important hallmark in the apoptosis pathway. To confirm the result, cytochrome $\mathrm{c}$ release from mitochondria to cytosol was detected and quantified by flow cytometer. Based on the result, pomegranate juice treated A549 cells did release the cytochrome $\mathrm{c}$ from mitochondria into cytosol after $24 \mathrm{~h}[\mathrm{p}<0.05]$ and $48 \mathrm{~h}[\mathrm{p}<0.01]$ exposure times. 


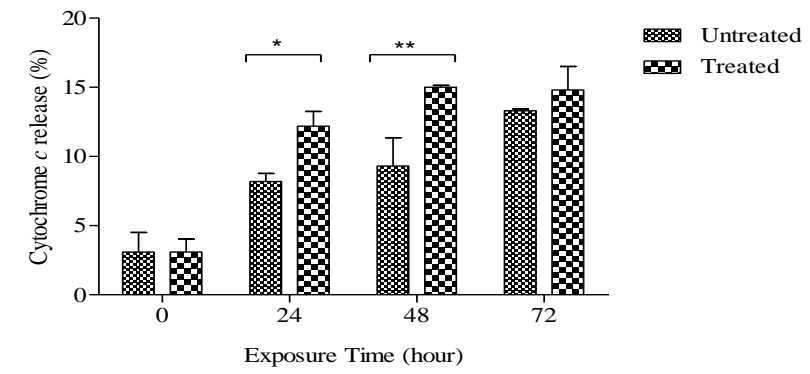

Fig 4: The effect of pomegranate juice on cytochrome c release in A549 cells. A549 cells were seeded at $1 \times 10^{4}$ cells $/ \mathrm{ml}$ in $5 \mathrm{~cm}^{2}$ plates and grown for $48 \mathrm{~h}$. After $48 \mathrm{~h}$ of growth, cells were treated with $2 \%$ pomegranate juice or left untreated. After each time of exposure, cells were harvested, permeabilized, fixed and stained with Anti-Cytochrome c-FITC before being analyzed by flow cytometer. The results were expressed as mean \pm S.E.M ( $n=2)$. Results were analyzed statistically using two-way ANOVA with Bonferroni post-test, show significant differences of cytochrome $\mathrm{c}$ release between untreated and treated A549 cells (* where $\mathrm{p}<0.05$ and ** where $\mathrm{p}<0.01)$.

\section{Conclusion}

In response to poor survival rate of lung cancer, other option in cancer treatment should be investigated despite of only relying onto the existing conventional therapies. Cancer prevention using natural products has been shown to be a potential alternative to reduce the risk of getting cancer as well as to prevent the recur rence of cancer. In this study, it was shown that pomegranate juice could be a potential agent in cancer intervention as it has the ability to suppress the growth of A549 cells and induced apoptosis. Further studies on toxicology profiles of pomegranate juice in vivo are warranted so it can be extended positively to hinder the lung cancer progression.

\section{Acknowledgements}

The works described herein have been supported by Exploratory Research Grant Scheme (ERGS 13-014-0047), Ministry of Education Malaysia. We would also like to thank Encik Jamaruddin Mat Asan from Immunology Department, School of Medicine, USM for the technical supports provided in flow cytometry analysis.

\section{References}

[1] Abdul Ghani, R., Jamil E.F, Nor Azahan Shah NAM, Nik Abdul Malek, NNA. The role of polyamines in anti-proliferative effect of selected malaysian herbs in human lungadenocarcinoma cell line. Jurnal Teknologi,2015. 77 (25), 0 pp. 137-140

[2] Siegel RL, Miller KD, Jemal A. Cancer Statistics, 2017. CA Cancer J Clin. 2017 Jan;67(1):7-30

[3] Gullet, N. P., Ruhul Amin, A. R. M., Bayraktar, S., Pezzuto, J. M., Shin, D. M., Khuri, F. R., Aggarwal, B. B., Surh, Y., \& Kucuk, O. Cancer prevention with natural compounds. Seminars in Oncology.2010. 37(3): 258-281

[4] Saunders, F. R., \& Wallace, H. M. On the natural chemoprevention of cancer. Plant Physiology and Biochemistry.2010, 48: 621-626

[5] Abdul Ghani,R., Nik Abdul Malek, NNA, Md Yusof, NF, Jamil EF. Ornithine decarboxylase gene expression in human lung adenocarcinoma cell (A549) treated with pomegranate juice. Jurnal Teknologi, 2015, 77 (25). , 0 pp. 95-99

[6] Turrini, E., Ferruzzi, L., \& Fimognari, C. Potential effects of pomegranate polyphenols in cancer prevention and therapy. Oxidative Medicine and Cellular Longevity, 2015.

[7] Adams, L. S., Zhang, Y., Seeram, N. P., Haber, D., \& Chen, S Pomegranate ellagitannin-derived compounds exhibit antiproliferative and antiaromatase activity in breast cancer cells in vitro. Cancer Prevention Research, 2010, 3(1): 108-113

[8] Jaganathan, S. K., Vellayappan, M. V., Narasimhan, G., \& Supriyanto, E.Role of pomegranate and citrus fruit juices in colon cancer prevention. World Journal of Gastroenterology.2014, 20(16): 4618-4625

[9] Nair, V., Dai, Z., Khan, M., \& Ciolino, H. P. Pomegranate extract induces cell cycle arrest and alters cellular phenotype of human pancreatic cancer cells. Anticancer Research. 2011, 31: 2699-2704

[10] Andrew Palmer, Radiah Abdul Ghani, Navneet Kaur, Otto Phanstiel, Heather Wallace. A putrescine ${ }_{i}$ anthracene conjugate : a paradigm for selective drug delivery. Biochemical Journal, 2009, 424. 0 pp. $431-438$

[11] Ouyang, L., Shi, Z., Zhao, S., Wang, F.T., Zhou§, T. T., Liu, B., \& Bao, J. K. Programmed cell death pathways in cancer: a review of apoptosis, autophagy and programmed necrosis. Cell Proliferation.2012, 45(6): 487-498

[12] Viurda-Martos, M., Fernández-López, J., \& Pérez-Álvarez, J. A. Pomegranate and its many fuctional components as related to human helath: a review. Comprehensive Reviews in Food Science and Food Safety.2010, 9: 635-654

[13] Lansky, N., Newman, R. A. Punica grantum (pomegranate) and its potential for prevention and treatment of inflammation and cancer. Journal of Ethnopharmacology. 2007, 109(2): 177-206

[14] Khan, N., Afaq, F., Kweon, M., Kim, K., \& Mukhtar, H.Oral consumption of pomegranate fruit extract inhibits growth and progression of primary lung tumors in mice. Cancer Research. 2007, 67(7): 3475-3482

[15] McIlwain, D. R., Berger, T., \& Mak, T. W. Caspase function in cell death and disease. Cold Spring Harbor Perspectives in Biology, 2013.

[16] Sakaue-Sawano, A., Kobayashi, T., Ohtawa, K., \& Miyawaki, A. Drug-induced cell cycle modulation leading to cell-cycle arrest, nuclear mis-segregation, or endoreplication. BMC Cell Biology. 2011, 12: $1-12$

[17] Dikmen, M., Ozturk, N., \& Ozturk, Y.The antioxidant potency of punica granatum L. fruit peel reduces cell proliferation and induces apoptosis on breast cancer. Journal of Medicinal Food. 2011,14(12): 1638-1646

[18] Kiraz, Y., Neergheen-Bhujun, V. S., Rummun, N., \& Baran, Y. Apoptotic effects of non-edible parts of punica granatum on human multiple myeloma cells. Tumor Biology. 2015, 1-13

[19] Ismail, T., Sestili, P., \& Akhtar, S.Pomegranate peel and fruit extracts: a review of potential anti-inflammatory and anti-infective effects. Journal of Ethnopharmacology. 2012,143(2): 397-405 